\title{
msatico
}

\section{Crônicas de}

El Dorado: uma

análise dos relatos

dos cronistas

espanhóis sobre

uma terra de

riquezas fabulosas

na América do Sul

(1536-1542)

Luiz Estevam de

Oliveira Fernandes ${ }^{1}$

Wederson de Souza

Gomes $^{2}$

\footnotetext{
1 Professor Doutor na Universidade Federal de Ouro Preto. Orientador do projeto de pesquisa pelo Programa Institucional de Voluntários de Iniciação Científica (PIVIC).

${ }^{2}$ Mestrando em História pela Universidade Federal de Ouro Preto. Projeto desenvolvido durante a graduação pelo PIVIC (Programa Institucional de Voluntários de Iniciação Científica).
}

\section{Chronicles of}

El Dorado: an analysis

of the Spanish

chroniclers' reports

about a land of

fabulous wealth in

South America

http://dx.doi.org/10.12660/rm.v7n10.2016.64728 


\section{Resumo:}

O presente trabalho analisa aquilo que se convencionou chamar dentro da historiografia de El Dorado. Através de análise dos cronistas que narraram as expedições em busca da Província e/ou Cacique dourado, e embasados no aporte historiográfico buscamos identificar aspectos descritivos do evento. Buscamos abordar diferentes cronistas, expedições e períodos para compreender o imaginário que circundaram o mito. Uma observação minuciosa do evento e seu caráter de representação evidenciaram o imaginário que perpassou a Europa Moderna e encontrou subsídio no Novo Mundo. El Dorado era uma região de grandes riquezas que de uma lógica racional ganhou um caráter mítico.

Palavras-chave: El Dorado, Maravilhoso, Novo Mundo, Expedições de Conquista.

\section{Abstract:}

The present work analyzes what is called "inside the historiography of El Dorado". Through analysis of the chroniclers who narrated the expeditions in search of the province, and/or golden Cacique, and grounded in the historiographical contribution we seek to identify descriptive aspects of the event. We address different chroniclers, expeditions and periods to understand the imaginary that circled the myth. The chroniclers produced between the sixteenth and seventeenth were essential for this work thorough observation of their representative character of an imaginary that pervaded Modern Europe and found benefit in the New World.

Keywords: El Dorado; Marverlous; New World, Expeditions of Conquest. 
Os séculos XV e XVI representaram um período de profundas mudanças no cenário europeu. A transição do período medieval para a Modernidade propiciou transformações na forma como os homens daquele período se relacionavam e enxergavam o mundo. A busca pelas especiarias da Costa Asiática ocasionou na chegada de Cristóvão Colombo ao Novo Mundo e após a expedição do genovês foram organizados diversos empreendimentos em direção àquele novo continente. Segundo Enrique Gandía, "na América, nos primeiros anos do descobrimento, as notícias vagas que eram dadas pelos índios sobre os Impérios do México, Chibchas e do Peru, vislumbrou regiões inconcebíveis e misteriosas, cheias de riquezas infinitas" (GANDÍA, 1929, p. 106).

Dentre os diversos empreendimentos que ocorreram no Novo Mundo, a procura por El Dorado obteve destaque, e por mais de três séculos mobilizou expedicionários que visavam encontrar a Província ou Lagoa do Dourado. Cobiçado pela possibilidade de uma riqueza aurífera inesgotável, o mito de El Dorado possui elementos operantes que o distingue dos demais mitos da conquista. Arraigado por influências que advém da Antiguidade Clássica e perpassa o maravilhoso medieval europeu, o mito doradista não ocorreu de forma isolada. Às notícias sobre a Província e/ou Lagoa de El Dorado estão sobrepostas ações, crenças, contato com a cultura indígena e experiências precedentes dos expedicionários.

Seja na forma de um reino completamente dourado ou na personificação de um índio que mergulhava em uma lagoa polvilhado por ouro, o mito se propagou mudando de características e região. As primeiras expedições que estão vinculadas à procura de El Dorado circundaram toda a região norte da América do Sul, todavia nunca foi encontrado qualquer indício real da sua localização ou existência. Demetrio Ramos Perez afirma que "EI Dorado no existía en ninguna parte, pues era fruto de la concreción de las ideas clásicas sobre indicios de posibilidad que el conquistador acumuló, por el paso de unas a otras huestes, sobre un supuesto racional" (RAMOS PEREZ, 1973, p. 462). A impossibilidade de encontrar El Dorado fez com que ele ganhasse um caráter mítico, sem, contudo, que cessassem as expedições de procura.

\section{Os mitos da conquista e as possibilidades de um El Dorado}

Quando pensamos em El Dorado e sua singularidade faz-se necessário um entendimento das operantes do mito que possui desde aspectos maravilhosos até uma racionalidade empírica característica da primeira modernidade. Analisar esses traços do pensamento quinhentista permite uma avaliação mais adequada do mito.

Compreende-se o maravilhoso como uma categoria de compreensão do mundo presente em um amplo espectro de tempos e espaços. Mas nem por isso o que se entendia por maravilha foi sempre a mesma coisa. Para que possamos compreender o maravilhoso em qualquer sociedade ou civilização é importante analisar o vocabulário do período. 
Jacques Le Goff faz tal afirmação em sua obra O Maravilhoso e o Quotidiano no Ocidente Medieval (LE GOFF, 1983: 17). Um elemento importante para compreensão do maravilhoso refere-se à herança, algo que se recebe, podendo ser moldado ou adaptado. Várias sociedades receberam algum legado do maravilhoso que pertence às camadas mais antigas do corpo social. No cristianismo, todavia, temos uma herança pouco significativa do maravilhoso.

Le Goff pondera que há um maravilhoso cristão, mas que não se trata de uma representatividade significativa. "O sobrenatural, o miraculoso, que constituem o que é o princípio do cristianismo, parecem diferentes, por natureza e função, do maravilhoso, embora tenham marcado com seu selo o maravilhoso cristão" (LE GOFF, 1983, p. 18). Segundo Le Goff, o maravilhoso foi uma forma de resistência à ideologia oficial do cristianismo, o miraculoso, por sua vez, referia-se a aspectos sobrenaturais e encerrava-se como elemento restrito do vasto domínio do maravilhoso.

Na transposição da Idade Média para o princípio da Modernidade alguns elementos do maravilhoso passam a ser encarados de forma diferenciada. Durante o empreendimento da conquista e o primeiro contato com o Novo Mundo, Colombo discerne bem entre monstruosidade e maravilhas. A monstruosidade significaria uma violação física das normas universais, já as maravilhas seriam as percepções físicas que causam espanto. "Colombo não pretende descartar a possibilidade do monstruoso, mas limita escrupulosamente suas pretensões de tê-lo contemplado; já o maravilhoso, observa-o em primeira mão, repetidas vezes" (GREENBLATT, 1996, p. 102). Stephen Greenblatt cita uma passagem de Alberto Magno que representa o maravilhamento de forma relevante. Segundo o crítico literário a sensação do maravilhamento se define como uma compressão e suspensão do coração causado pelo espanto diante a aparência sensível de algo encantador, tão grande e tão excepcional que o coração sofre uma forte contração (GREENBLATT, 1996, p. 110).

"O maravilhoso, portanto, se propõe como expressão de um critério de diferenciação cultural entre valores de referência propícios a instaurar uma comunicação entre o autor, seu público e as prerrogativas de um mundo disforme" (LANCIANNI, 1991, p. 22).

A busca por compreensão e explicação de El Dorado suscita importantes reflexões que extrapolam o mito e exigem uma compreensão pormenorizada do imaginário. Para além do pensamento maravilhoso e medieval que é repleto de elementos metafísicos, o que se percebe na busca por um território portentoso e paradisíaco são traços de um ideário que remonta muito dantes, desde a Antiguidade.

Johnni Langer pontua que partir de fins do século XV, a Europa foi acometida de um grande retorno à mitologia clássica e a nostalgias perdidas, através da literatura, pintura, escultura e da poesia. Em parte, pelas novas terras descobertas - que reavivaram esses símbolos enfraquecidos no imaginário europeu - e também pelas mudanças culturais efetuadas pelo renascimento clássico, que antecedeu a formação dos mitos americanos 
(LANGER, 1997:32). Fernando Aínsa, por seu turno, destaca que a conquista americana oscilou entre dois polos tensionais: a Idade de Ouro e o El Dorado. De certa forma, essa tensão já estava enunciada desde os gregos, que concebiam que a partir do Mar Mediterrâneo existiam três continentes, cujo mundo grego representava o centro. A comunicação entre os demais continentes seria o elemento que quebraria esse equilíbrio paradisíaco. A navegação trazia consigo o caos, pois ela permitia a comunicação entre as partes do mundo que foram separadas pela ordem natural.

Os grandes filósofos da Antiguidade Grega, revela-nos Aínsa, acreditavam que a Idade do Ouro representava um paraíso idílico onde o homem vivia em paz, sem corrupção. A natureza fornecia àqueles homens todos os alimentos necessários, sem que estes precisassem trabalhar ou disputar esses alimentos. A Idade do Ouro remonta uma ideia de paraíso na terra, paraíso esse que só poderia ser mantido através do isolamento e do distanciamento. O homem da Idade do Ouro deveria aceitar aquilo que tinha para manutenção de sua felicidade (AINSA, 1998, p. 86).

Hilário Franco Jr., no mesmo sentido de Aínsa, aponta que o primeiro mito da humanidade possivelmente tenha sido a condição perfeita perdida, ou seja, o paraíso perdido. No ocidente medieval esse sonho coletivo estava alicerçado na Bíblia que se abre e fecha com o paraíso. A Idade Média que havia herdado elementos de inúmeras sociedades oscilava em duas concepções temporais diferenciadas. Uma temporalidade cíclica de herança greco-romana, em que, a sociedade retornaria, em algum momento, àquele Paraíso perdido. Em outra perspectiva, a judaico-cristã, tínhamos uma temporalidade linear, cujo homem caminharia para o fim, todavia o Paraíso do fim dos tempos não podia ser o do princípio. A cultura popular medieval, que ainda idealizava o tempo de forma circular, enxergava o Paraíso, ao qual os justos terão acesso, como sendo o Paraíso primitivo. O Novo Mundo se insere nesse contexto como uma região paradisíaca que permitiria recuperar a Idade do Ouro e daí a possibilidade de se encontrar elementos portentosos que iam além da realidade física.

O maravilhamento e o paradisíaco orientavam fortemente a forma de enxergar o mundo dos conquistadores que partiam da Europa e desbravavam o Novo Mundo em busca de riquezas, prestígio e ascensão social. Todavia, como assevera Demétrio Ramos Perez, todos os relatos relacionados ao mito doradista apresentam-nos uma tese vinculada à história das ideias. Tal tese é parcialmente contrária à noção de que apenas elementos maravilhosos fundamentaram as expedições primitivas relacionadas a El Dorado; ao contrário, para o autor, havia por detrás delas forte embasamento empírico e anti-mítico. A expedição de Diego de Ordás $^{1}$ que é apresentada como uma das precursoras do mito de El Dorado no continente americano na verdade foi planejada racionalmente e alicerçada nas experiências adquiridas nos empreendimentos ocorridos em México-Tenochtitlán e no Peru.

El Dorado, mais que existir concretamente, germinava da mente e foi o resultado de

\footnotetext{
${ }^{1}$ Diego de Ordás foi um distinto capitão e expedicionário de Hernan Cortés durante a empresa de conquista de México-Tenochtitlán. Participou inclusive no processo de conquista da Ilha de Cuba.
} 
um conjunto de elementos reais. O entendimento da realidade histórica que possibilitou a crença no mito estabelece que seja retraçado um mapa das expedições. É preciso ter em mente que elas não são distintas entre si e estavam intrinsicamente conectadas. A forma como o mito proliferou teve o impulso de ideias, experiências e referências distantes da localização geográfica. Ramos Perez aponta um importante questionamento para desenvolver a sua perspectiva. "Como se explica o que chega a ser, precisamente, o suporte do mito? E mais ainda, o que possibilitou sua revitalização exultante? " (RAMOS PEREZ, 1973, p. 3). E complementa afirmando que a gênese pode seguir caminhos diversos, poucas vezes retilíneos e isso impossibilita encontrar uma linha progressiva para o acontecimento.

A compreensão da ideia racional do mito de El Dorado sugere pensar operações empreendidas desde a primeira viagem de Colombo e a conquista da Nova Espanha. 0 genovês havia calculado previamente onde se situavam as ilhas e as cidades. $O$ convencimento de Colombo e a crença de estar na região asiática fez com que ele não desconfiasse que estivesse em outro território. Após o choque de não terem sido encontradas as ilhas asiáticas, consideradas autênticas pelos relatos de Marco Polo e Mandeville, formou-se um vazio difícil de superar e era necessário substituir por algo concreto. Tendo em vista que o imaginário propicia várias fábulas, os conquistadores posteriores examinariam todas as possibilidades para cumprir esse vazio. Os objetivos asiáticos, que até então estiveram vigentes, foram substituídos pelos mitos atlânticos. Como apresentamos, nesse momento ressurgem as velhas fábulas sobre as ilhas da eterna felicidade ou juventude eterna e também as influências medievais e renascentistas. Esse eixo temático, ou seja, a antiguidade clássica paradisíaca e o maravilhoso medieval serviram de estrutura para Cortés e sua empresa quando a ilusão asiática havia sido descartada.

Não há relevância em retraçar e expor todo o processo do empreendimento de Cortés, mas pontuar suas ideias que teriam sido relidas pelos caçadores de El Dorado. Cortés opera a conquista do Império Asteca no mesmo momento em que "tudo parecia inclinar para as costas asiáticas, finalmente encontradas; quando toda atenção se colocava no velho empenho renascido, incluindo a vontade do próprio Cortés" (RAMOS PEREZ, 1973, p. 6). Quando a busca pelo continente asiático reacende e, a Nova Espanha parecia não ser tão atrativa, a empresa de Cortés reaviva a chama e mostra um território rico e próspero. Os empreendimentos que sucederam a empresa de Cortés buscavam terras nunca vistas e ouvidas, ou seja, uma segunda Nova Espanha.

As primeiras informações da Província da Meta, aquela que seria considerada como a precursora de El Dorado, apresentam aspectos relevantes para que possamos compreender a transmissão das notícias e a forma como operou esta difusão. As ações empreendidas por Ordás sofriam influências das empresas de Cortés e Pizarro. Ramos Perez aponta que em 12 de setembro de 1529, Ordás teria recebido a proposta de iniciar a empresa de conquista na região do Rio da Prata e ressalta que o expedicionário de Cortés tinha referências sobre as riquezas argentíferas daquela região (RAMOS PEREZ, 1973, p. 18). O conquistador reflete durante meses sobre o assunto, procura por informações e pessoas que estivessem inteiradas, e só assim recusa a empreitada. Apesar dos incentivos de próspera fortuna, 
testemunhos de outros conquistadores e mesmo com a possibilidade de assumir o controle na região do Rio Prata, o conquistador escolhe se dirigir para o território do Maranhão e da Paria no ano de 1530. A recusa pela região do Prata estaria alicerçada em conhecimentos empíricos do período, no qual a localização geográfica do local fazia com que ela fosse menos atraente que os territórios do Maranhão e da Paria.

Em recente trabalho, a historiadora Maria Izilda Santos de Matos analisa o relato do Frei Gaspar de Carvajal $^{2}$ e apresenta traços valiosos para compreensão do imaginário quinhentista. "Desde os finais da Idade Média, existiam preceitos que os climas eram determinantes da distribuição dos metais" (MATOS, 2012, p. 190). A produção argentífera e aurífera no período estava associada às posições geográficas da região (latitude/longitude) e esse era um dos condicionantes para que os conquistadores se lançassem em busca das regiões e suas riquezas. Ramos Perez aponta esse viés como um dos elementos que suscitou a predileção de Ordás pelo norte equatorial. Os letrados e teóricos do período consideravam que os metais eram como plantas e que regiões mais próximas aos trópicos seriam mais favoráveis para que encontrassem ouro, devido a sua maior proximidade do Sol. O ouro estaria no círculo equatorial, logo a região do Rio da Prata que estava abaixo da linha equatorial era menos atraente.

O ideário de que metais são como plantas na terra percorreu todo o século XVI até o século XVII, pois, segundo Ramos Perez, Herrera y Tordesillas ${ }^{3}$ afirma que os metais são como plantas escondidas nas entranhas da terra. A conclusão que Ramos Perez apresenta sobre a análise é: "He aquí, pues, sobre tierras concretas del intertrópico, la cualificación de una esperanza racional, operando claramente en sustitución tanto de los arrumbados supuestos asiáticos como de los mitos legendarios" (RAMOS PEREZ, 1973, p. 24).

A análise produzida por Ramos Perez é confirmada nos relatos produzidos por Fernández de Oviedo ${ }^{4}$. As primeiras expedições em busca da região da Meta datam do ano de mil quinhentos e trinta e dois. Fernández de Oviedo apresenta em seus relatos que Ordás partiu no dia vinte três de junho de mil quinhentos e trinta e dois rumo ao Rio Huyapari ${ }^{5}$ acima em busca de riquezas auríferas.

O empreendimento de Ordás tinha como pressuposto o êxito de Cortés, todavia ele não tinha as mesmas condições e não pôde seguir adiante com sua empresa. Apesar da retirada estratégica, as suspeitas de uma próspera região aurífera foram confirmadas e a existência de pessoas contrariadas por não continuar o trajeto serviria de motor para que

\footnotetext{
${ }^{2}$ Expedição na região do Quito, momento onde El Dorado aparece em relatos e correspondências.

${ }^{3}$ O Cronista Maior de Castela escreveu sua obra História Geral dos Feitos Castelhanos nas Ilhas e Terra Firme do Mar Oceano no ano de 1615. Ainda no século XVII continuavam a ponderar essa lógica dos metais como plantas.

${ }^{4}$ Gonzalo Fernández de Oviedo y Valdés narra no Livro XXIV do capítulo III, p.216 do Tomo Primeiro da Segunda Parte como ocorreu a expedição de busca pela Província da Meta nos arredores do Rio Huyapari (Orinoco).

${ }^{5}$ Segundo Gonzalo Fernandes de Oviedo y Valdés, Huyapari foi o nome dado pelos espanhóis ao Rio Orinoco. Orinoco era a denominação utilizada pelos indígenas que habitavam seus arredores. Idem Fernández de Oviedo, p. 216.
} 
retornassem futuramente. Os conquistadores se mobilizariam facilmente pela fama da província da Meta e então a conquista se tornaria uma realidade. Ramos Perez reforça que o importante era saltar de uma suposição para uma certeza e não permitir que aquilo escapasse de suas mãos. Entretanto, Ordás não poderia presumir o efeito que aquilo causaria ao longo do tempo em empresas posteriores.

A racionalidade defendida por Ramos Perez é aristotélica, ou seja, baseada em premissas, mais do que na experiência. O que ocorre nesse caso é uma feliz sobreposição entre premissa e experiência, em que a última parece confirmar a primeira. Por isso, quando as coisas não se concretizavam o erro era do conquistador. A experiência adquirida por aquele expedicionário havia fracassado, contudo outros obtiveram sucesso antes. Ordás e o precipitado de previsión, que se adiantam às sugestões que surgiriam com a Conquista do Peru. Ou seja, de onde vinha o ouro do Caribe se o Caribe não tem muito ouro? De onde veio o ouro para o resgate de Atahualpa? Devia haver uma fonte. Se o cálculo apriorístico está atrelado à ideia de um país aurífero incerto e sem nome, isso é resultado de uma avaliação teórica e das condições naturais. A ausência de motivações míticas e uma matriz racional apoiada na experiência estariam enraizadas na empresa de Cortés.

O trabalho construído por Ramos Perez busca nas expedições de conquista do Novo Mundo elementos que comprovem a sua tese, ou seja, empreendimentos empíricos e racionais. A lagoa de Tenochtitlán é um dos motores que serviu de referência aos conquistadores. Quando expedicionários posteriores se lançaram em busca de regiões auríferas mostravam ouro e prata para que assim os indígenas thes indicassem o direcionamento e o que seria encontrado. Os relatos indígenas sugeriam uma mescla de verdades e mitos, tal como observa Matthew Restall. "Segundo os estudiosos da Mesoamérica, área civilizacional que abrangia a maior parte do México e da América Central, os nativos não reconheciam distinção entre mito e história" (RESTALL, 2006, p. 19). Desta forma, o aparato cultural do conquistador em contraste com a cultura dos índios criava distorções e estas distorções metamorfoseavam a concepção dos novos empreendimentos.

Ramos Perez defende que, inicialmente, a procura por ouro não tinha relação com El Dorado. As expedições que se tornaram referência do mito aconteceram com um embasamento racional, porém as novas conquistas e o contato com diferentes impérios e riquezas americanas forneceram elementos para que o mito permanecesse vivo. Essa também é a conclusão defendida por Langer em sua análise sobre as expedições de busca por El Dorado. O historiador assevera que os europeus afirmaram compreender as descrições indígenas, criando assim o mito. O que ocorreu, porém, foi uma adaptação improvisada dos supostos diálogos, a conquista também está presente na troca de palavras. A formação do mito confirmou essa relação (LANGER, 1997, p. 38).

Os autores supracitados trabalharam com orientações diferenciadas sobre o relacionamento dos castelhanos com o portentoso, paradisíaco e empírico. O que percebemos, entretanto, é que à busca de El Dorado estão entrelaçadas essas diferentes perspectivas. As operantes do mito incluem aquilo que Greenblatt considera como um 
maravilhamento, no qual o instável, movediço, e não apenas o signo se fizeram presentes. 0 Novo Mundo suscitando a crença de um paraíso presente demonstra a leitura e interpretação daqueles homens sobre a realidade. Misturavam-se às suas expectativas as esperanças bíblicas e as leituras de poetas e filósofos da antiguidade. O elemento empírico corrobora. Apesar da mescla entre a fábula e o real os conquistadores eram homens que possuíam um pensamento apriorístico. Essa evidência é clara até mesmo na forma como eles lidam com o mito de El Dorado, as expectativas são produzidas através de experiências precedentes.

O El Dorado que se constrói no Novo Mundo incorpora à sua matriz diversos conhecimentos acumulados. Os cronistas narram suas experiências, expectativas, crenças e os referidos autores apresentados realizam considerações relevantes para enxergar a estrutura do mito.

\section{Crônicas de El Dorado: Sua origem primitiva e formalização}

A historiografia sobre a busca por El Dorado é tímida e pouco destacada. Existem trabalhos que tocam no tema, mas, por vezes com um enfoque em outras questões que não especificamente o mito. Os trabalhos mais recentes como o das pesquisadoras María Jesús Benítes e Maria Izilda Santos de Matos buscam analisar a expedição de Gaspar de Carvajal, todavia o interesse de ambas é centrado nas amazonas, outro traço marcante das expedições de conquista e que estão atreladas a El Dorado.

No que se refere ao presente trabalho, Matos destaca que no Quito circulavam narrativas sobre a existência do País da Canela, localizado no Oriente equatorial (MATOS, 2012, p. 190). Benítes assevera que a lenda original de uma lagoa (a Guatavita), cujo seu leito encontrava-se uma quantidade incomensurável de ouro, produziu um dos mitos mais persistentes e trágico processo de conquista e colonização: El Dorado. Tanto o país da Canela e a lagoa do Cacique Dourado situavam-se em algum lugar na vasta selva oriental (JESús, 2008, p. 55). O Quito, como asseverado pelas autoras, é o ponto de partida para concretização e formalização do mito e será objeto de nossa análise a seguir.

Gonzalo Fernández de Oviedo ${ }^{6}$, Primeiro Cronista do Novo Mundo, percorreu diversas regiões do continente americano e isso lhe permitiu observar inúmeras ocorrências. Fernández de Oviedo em sua obra História General y Natural de las Indias realizou uma significativa descrição e "representação" da Província do Quito7. O trabalho realizado por

\footnotetext{
${ }^{6}$ Nasceu e morreu em Madrid (1478-1557), participou da Conquista do Reino de Nova Granada, teve uma longa permanência na Itália e esteve no continente americano, onde pode recorrer e contemplar a testemunhos de forte observação. Relevante para historiografia, seus relatos o transformaram em primeiro cronista do Novo Mundo. Horacio Jorge Becco apresenta essa descrição na compilação de crônicas referentes às buscas por El Dorado, "Crónicas de El Dorado". Biblioteca Ayacucho, p. 1, 2003.

${ }^{7}$ Quito (originalmente San Francisco de Quito) é hoje a capital e a segunda maior cidade do Equador, localizada no noroeste da América do Sul. À época sobre a qual escrevemos, era conhecida como Província do Quito, após a conquista de Sebastian de Benálcazar a região foi rebatizada e passou a ser chamada de San Francisco de
} 
Fernández de Oviedo tem grande relevância, pois sua minuciosa relação pode ser compreendida como uma construção etnográfica de várias regiões do Novo Mundo, inclusive do Quito.

As análises historiográficas sobre os cronistas do período apontam que a Província do Quito se apresentava como uma região rica em canela e também onde teriam feito menção à existência del Dorado. A região do Rio Huyapari (Orinoco) também foi proeminente em riquezas e, foi nas suas encostas que surgiram as primeiras informações sobre a Província da Meta, além da descrição de ritos culturais que mais tarde serão incorporados ao mito.

As crônicas produzidas no Novo Mundo foram de suma importância para compreensão e representação do novo continente, além de servir como referência para conquistadores a posteriori. Como ressalta Roger Chartier, a circulação multiplicada de escritos impressos modificou as formas de sociabilidade, sendo inclusive o responsável por permitir novos pensamentos e transformar as relações de poder durante o período do Antigo Regime nos séculos XVI e XVII. É preciso entender que a leitura desses escritos não se trata apenas de uma operação abstrata de intelecção. É preciso pôr em jogo o corpo, se inscrever num espaço e em uma relação consigo ou com outro (CHARTIER, 1991, p. 178). Os escritos produzidos tinham objetivos e intencionalidades implícitos, ou seja, exaltar os sucessos e garantir retorno dos esforços e recursos investidos.

Juan $\mathrm{Gil}^{8}$, importante catedrático, destaca que no ano de mil quinhentos e trinta e nove apareceu o primeiro escrito que fazia menção ao nome de El Dorado ${ }^{9}$. Gil ressalta que essa denominação foi dada na região do Quito pelo expedicionário Sebastian de Banalcazar para designar um cacique que "segundo se dizia, se lavava todo dia desnudo e ao sair ungido com resina, se polvilhava de ouro em pó, e esta era sua única vestimenta, pois era algo maravilhoso o resplendor que exibia seu corpo" (GIL, 1989, p. 65). O catedrático, entretanto, ressalta que essa é uma explicação que surgiu posteriormente, a partir de um conteúdo vazio que datava de muito antes.

A difusão e distorção do mito ficam mais evidentes quando Gil pondera que a "primeira menção manuscrita não faz qualquer alusão ao índio cacique que tanto dará o que falar depois de Fernández de Oviedo e historiadores posteriores, cada um deles embelezou a lenda com características mais exóticas" (GIL, 1989, p. 65). Inicialmente El Dorado apareceu como o nome de uma região, a qual Benalcázar saiu em demanda e de onde se ouvia muitas notícias sobre ouro e pedras ${ }^{10}$.

\footnotetext{
Quito.

${ }^{8}$ Juan Gil foi catedrático de Filología Latina de la Universidad de Sevilla.

${ }^{9}$ Juan Gil aponta em sua obra Mitos y utopías del Descubrimiento (III - El Dorado) como teriam sido difundidas as primeiras notícias escritas sobre El Dorado.

${ }^{10}$ Antonio de Herrera y Tordesillas. Historia General de los hechos de los Castellanos en las Islas y tierra firme del Mar Océano. Década V. Libro VII. Capítulo XIV. Madrid, 1615, p.225 narra que Benalcázar soube sobre a província do Dourado na região do Quito e resolveu sair em busca.

${ }^{10}$ Fernández de Oviedo faz essa importante descrição no Libro XLV. CAP I, Terceira Parte - TOMO IV, p. 136 da
} 
Os relatos acerca da região do Quito e os arredores do Rio Huyapari, a exaltação daquelas riquezas e, por conseguinte, de sua localização, serviram como referências para impulsionar a busca e concretizar o mito de El Dorado. Os empreendimentos posteriores à empresa de Ordás se pautavam naquelas vultosas descrições. Sebastian de Benalcazar, Gonzalo Jiménez de Quesada e também Gonzalo Pizarro, importantes conquistadores do século XVI, se utilizaram desses relatos para seguir adiante com suas expedições.

A Meta, província primogênita cujas riquezas eram tão atraentes, mostrava que após o Império Asteca e Peru Incaico, ainda poderia ser encontrada uma região ainda mais promissora. Quando Ordás interrompeu o trajeto ao longo do Huyapari ele semeou a esperança e acendeu o estopim para novos empreendimentos. As encostas do Rio Huyapari e a província do Quito foram os referenciais para difusão da fama e crença de que El Dorado existisse. A assimilação das Províncias da Meta e Quito reafirmavam a existência daquele que poderia ser o terceiro reino ${ }^{11}$ e também a fonte das inesgotáveis riquezas encontradas.

\section{El Dorado: um índio dourado, uma lagoa e uma terra rica em canela}

Como destacado anteriormente, as expedições primitivas vinculadas à busca de El Dorado nada mais eram do que empresas de conquista cujo objetivo principal era encontrar grandes reservas auríferas. Um exame criterioso das fontes e da historiografia sobre o tema mostra que na verdade ocorreu uma sobreposição entre elementos empíricos e míticos.

Analisando as relações produzidas pelos cronistas Antonio de Herrera y Tordesillas e Gonzalo Fernandez de Oviedo é possível entrever como e onde se deram as informações sobre El Dorado e também acerca da existência de um território com uma enorme quantidade de canela. Fernández de Oviedo em sua obra Historia General e Natural de las Indias, apresenta que o capitão Sebastian de Benalcázar havia lhe dito pessoalmente na cidade de Santo Domingo sobre a existência de um território com quantidade abundante de canela. Sebastian de Benalcázar foi um importante conquistador do Novo Mundo, militou em terra firme, nas províncias e governo de Castela do Ouro no tempo do governador Pedrarias Dávila, em meados dos anos de mil quinhentos e quatorze. Reconhecido por Dávila como um bom homem, seguiu para a governação de Honduras juntamente do capitão Diego Albitez, um escrivão e outras pessoas. Mais tarde Benalcázar veio a conhecer os capitães Almagro e Pizarro vindo a se tornar o tenente da região do Quito e posteriormente fundou a cidade de São Francisco ${ }^{12}$.

Fernández de Oviedo ressalta que Sebastian de Benalcázar havia lhe dado tal notícia

\footnotetext{
História Geral e Natural das Índias como se deu a ascensão e o sucesso militar de Sebastian de Benalcazar.

11 Juan Gil aponta que Antonio Sedeño e Gerónimo Ortal em meados de 1535 estavam procurando a província da Meta. Estando em Porto Rico, houve um verdadeiro frenesi por acreditarem que haviam encontrado o outro Peru. Mitos e utopias del descubrimiento. Vol.III: “El Dorado". Madrid, Alianza Editorial, p. 35, 1989.

12 Fernández de Oviedo faz essa importante descrição no Libro XLV. CAP I, Terceira Parte - TOMO IV, p. 136 da História Geral e Natural das Índias como se deu a ascensão e o sucesso militar de Sebastian de Benalcazar.
} 
no momento em que retornava à Espanha e que também havia se tornado governador de Popayán. Durante o conflito entre os índios do Quito e suas comarcas, Benalcázar teria ouvido falar sobre este local onde haveria grande quantidade de canela, além de ouro e prata.

é aqueste Benalcáçar desde estonces tuvo noticia mucha de la canela, é aun segund él me dijo en esta ciudad de Sancto Domingo, cuando tornaba de España proveydo por gobernador de Popayan, su opinión era que hácia el rio Marañón la avia de hallar, é que aquella canela se avia de llevar á Castilla é á Europa por el dicho rio, porque segund los indios le avian dado noticia del camino, pensaba él que no podía faltar, si su información no fuese falsa; la qual tenía por çierta é de muchos indios (FERNÁNDEZ DE OVIEDO, 1855, p. 382).

A província do Quito e o tenente Sebastian de Benalcázar estavam sob o comando militar do Marquês Francisco Pizarro. Ao saber da traição de Benalcázar ${ }^{13}$, o Marquês enviou seu irmão Gonzalo Pizarro para assumir a governação do Quito. Benalcázar havia partido para o Reino da Nova Granada onde Jiménez de Quesada havia descoberto as minas de esmeraldas. Este elemento foi primordial para a ascensão do capitão Benalcázar ao governo de Popayan. Após fazer menção às ações de Benalcazar e sua descrição sobre o Quito, Fernández de Oviedo descreve a existência de um cacique dourado ao qual Gonzalo Pizarro objetivava encontrar. O relato de Fernández de Oviedo aponta que Francisco Pizarro soube da deserção do capitão Benalcázar e enviou seu irmão Gonzalo Pizarro para que este se apropriasse daquele território e, por conseguinte, buscasse a província da canela e o cacique da lagoa dourada.

O primeiro cronista também narra que ao questionar os espanhóis sobre a razão do cacique ser chamado de Rei Dourado, eles respondiam que esta informação teria sido relatada pelos habitantes da Província do Quito.

Que lo que de esto se ha entendido de los indios, es que aquel gran señor o príncipe continuamente cubierto de oro molido y tan menudo como sal molida; porque le parece a él que traer otro cualquier atavío es menos hermoso y que ponerse pinzas o armas de oro labradas de martillo os estampadas, o por otra manera, es grosería y cosa común, y que otros señores y príncipes ricos las traen cuando quieren; pero que polvorizarse con oro es cosa peregrina, inusitada y nueva y más costosa (BECCO, 2003, p. 6).

O trecho citado descreve parte do processo ritualístico do Cacique Dourado. Através

\footnotetext{
${ }^{13}$ Benalcazar partiu em direção ao Reino da Nova Granada sem pedir licença àquele que seria o seu superior, o Marquês Francisco Pizarro. Fernández de Oviedo aponta no capítulo que era algo frequente, onde os capitães faltavam aos seus superiores. Essa descrição está contida em Gonzalo Fernández de Oviedo y Valdés. Livro XLIX., CAP I., Terceira Parte - TOMO IV, p. 380.
} 
dessa descrição, Gonzalo Pizarro ${ }^{14}$ partiu em busca de uma terra que ele acreditava possuir prósperas riquezas e consequente sucesso. O ritual do cacique dourado é um importante elemento descritivo, não apenas por guardar aspectos culturais daquele território, mas também por ser uma das notícias primitivas que produziram um aspecto mítico a El Dorado.

Antonio de Herrera y Tordesillas ${ }^{15}$, Cronista Maior das Índias, descreve em sua obra História Geral dos Feitos Castelhanos nas Ilhas e Terra Firme do Mar Oceano sobre a Província da Meta e El Dorado. Ramos Perez evidencia que as crônicas produzidas por Herrera y Tordesillas reafirmam que as províncias da Meta e El Dorado se referiam a um território com incomensuráveis riquezas. Estas fortunas auríferas e argentíferas seriam a motivação de inúmeras expedições de busca e conquista dessas províncias desde os tempos de Diego de Ordás. Herrera y Tordesillas corrobora a narração de Fernández de Oviedo sobre as primeiras informações de El Dorado e também descreve aspectos referentes à conquista que ocorrera na província quiteña.

O Cronista Maior descreve que Sebastian de Benalcazar teria sido informado a respeito de El Dorado na província do Quito ${ }^{16}$, no ano de 1534 . Segundo a narração de Herrera y Tordesillas, Benalcazar teria ouvido de um índio que a região do Quito era rica em ouro e prata e que a quantidade era tão grande que seus cavalos não poderiam levar a vigésima parte. O índio Yrruminavi, conhecido como capitão do Quito, ao saber da chegada dos espanhóis começou a retirar todo ouro que pôde e, os demais habitantes daquele povoado começaram a abandonar suas casas. Antes de partir, os índios incendiaram toda a aldeia, incluindo o palácio real. Todos aqueles que se mostravam contrários à partida eram mortos por Yrruminavi e seus companheiros. Benalcázar e os demais soldados que o acompanhavam não tiveram dificuldades em adentrar a região do Quito, porém ao chegar ao local não encontraram o aguardado tesouro. Benalcázar iniciou interrogatórios aos índios que estavam no local objetivando descobrir o paradeiro das riquezas. Após constantes interrogatórios e o apoio dos índios Canarias - estes apontados por Herrera y Tordesillas como confederados dos espanhóis -Benalcázar conseguiu capturar Yrruminavi e lhe impôs terríveis castigos que o levaram à morte.

A notícia de El Dorado chegaria ao tenente Benalcázar através de um dos seus capitães, chamado Luis Daza. Daza ao capturar um índio estrangeiro na região da Tacunga recebeu notícias de uma província conhecida como Cundinamarca, local onde existia um

\footnotetext{
14 Gonzalo Pizarro em correspondência aos reis de Castella no ano de 1542 pontua seu intento de ir à procura da Logoa del Dorado. Esse elemento é bastante curisoso, tendo em vista que o Frei Gaspar de Carvajal, capelão da expedição, produz uma extensa relação dos fatos e dentre os objetivos da conquista não é feita qualquer menção à busca del Dorado, mas sim de uma região de riquezas e da terra da canela. José Toríbio Medina apresenta a documentação referente à viagem ao longo do Rio Maranhão, dentre eles encontra-se a carta escrita por Gonzalo Pizarro aos reis de Castela onde ele apresenta seus objetivos e anseios para aquela viagem. A carta pode ser encontrada no capítulo Documentos, p.85 da obra Descubrimiento del Río de las Amazonas.

${ }^{15}$ Antonio de Herrera y Tordesillas conhecido como Cronista Maior das Índias foi o responsável por organizar e narrar os documentos referentes ao processo de conquista e colonização do continente americano

${ }^{16}$ Herrera y Tordesillas. Historia General de los hechos de los Castellanos en las Islas y tierra firme del Mar Oceano. Decada V. Libro VII. Capítulo XIV. Madrid, 1615, p. 225.
} 
senhor muito poderoso. O índio, que não tem o seu nome citado pelo Cronista Maior, teria afirmado que nessa região podiam ser encontradas inúmeras riquezas e que o território havia sido o motivo de diversas empresas de busca e descobrimento del Dorado ${ }^{17}$ que até o momento parecia encantamento. O Cronista Maior também relatou o fato de que Ordás buscava adentrar El Dorado ${ }^{18}$. Essa afirmação de Herrera y Tordesillas produziu um aparente equívoco, pois como Ramos Perez afirma "con ello, introdujo una lamentable confusión, pues al dar como objetivo de Ordás al oaís del Dorado, cuyo mito todavía estaba para nacer, escamoteaba de golpe todo proceso formativo" (RAMOS PEREZ, 1973, p. 5).

A análise documental e historiográfica apresenta dois aspectos relevantes sobre EI Dorado. Ao analisarmos a relação de Fernández de Oviedo é evidente que Gonzalo Pizarro está procurando um cacique dourado juntamente de uma região de grandes riquezas, todavia ele não deixa claro o que Benalcazar buscava. Herrera y Tordesillas, por sua vez, ao narrar o conflito de Benalcazar na região do Quito aponta El Dorado como uma província. A mudança do caráter das buscas de El Dorado incide diretamente com os estudos realizados por Enrique Gandía e Ramos Perez, com as quais temos uma explicação racional de caráter empírico acerca do mito.

O historiador argentino Enrique Gandía ${ }^{19}$ ao analisar os mitos da conquista americana em sua obra História crítica dos mitos da Conquista Americana realizou uma análise sobre El Dorado e as transformações que o mito sofreu. $O$ autor realiza um estudo das fontes e assinala que, ao contrário de que alguns historiadores afirmam, o processo ritualístico do índio Guatavita não é fantasioso. A cerimônia do dourado foi divulgada de forma alterada e, embora alguns a negassem e apontassem como uma invenção indígena, um estudo sobre as civilizações, ritos e costumes dos Chibchas provou que a cerimônia do índio dourado é historicamente correta.

As lagoas sempre tiveram destaque nos rituais indígenas como ficou claro na análise do cronista Fernández de Oviedo. A concretização do mito está ligada a este forte traço cultural, mas também a outros costumes indígenas que são evidenciados na análise de Ramos Perez. O território do Quito se apresentou como uma região centralizadora para a crença de El Dorado, no qual suas riquezas e suposições latentes a respeito daquela comarca cresciam fortemente. Sebastian de Benalcázar após receber as primeiras informações sobre a província do Dourado se lançou em uma jornada de busca para que pudesse encontrá-la. Gonzalo Pizarro logo após assumir a governação do Quito, recebe as primeiras notícias do Dourado e também parte em sua procura.

\footnotetext{
${ }^{17}$ Os relatos de Antonio Herrera y Tordesillas foram produzidos anos após as conquistas, todavia o que é válido ressaltar, nesse processo, é que o Cronista Maior, em geral, reproduzia aquilo que os demais cronistas produziram em suas expedições. A expressão que o cronista utiliza no capítulo XIV da Decada $V$ é exatamente Dorado.

${ }^{18}$ Herrera y Tordesillas. Historia General de los hechos de los Castellanos en las Islas y tierra firme del Mar Oceano. Decada IV. Libro X. Capítulo IX. Madrid, 1615, p. 218.

19 Exerceu docência na Escola Nacional de Belas Artes, na Universidade de Morón e na Universidade de Belgrano, tendo sido co-fundador dessas duas últimas, e também membro da Academia Nacional de História da Argentina.
} 
Ramos Perez questiona o fato de Gonzalo Pizarro ausentar-se da função de governador e investir num intento ainda não confirmado. O historiador aponta que Gonzalo Pizarro já tinha conhecimento das notícias sobre El Dorado e da Canela antes de sua chegada à Província do Quito. Ramos Perez ainda salienta que o fato de Gonzalo Pizarro se lançar na busca da Província da canela e a lagoa do Dourado favorece que o mito se concretize e propague rapidamente.

Outro ponto que Ramos Perez ressalta é exatamente as práticas dos índios que habitavam a região do Huyapari (Orinoco). Os índios se untavam desde a cabeça até a ponta dos pés com resinas e ouro em pó, renovando essa prática dia após dia. Essas práticas indígenas provavelmente foram assistidas e estavam na memória dos conquistadores desde os tempos de Ordás e, por conseguinte Gonzalo Pizarro teria associado o índio dourado a uma lagoa. Como Gandía também afirma "en las expediciones referidas no hemos comprobado la búsqueda del Cacique de Guatavitá, sino de regiones más o menos ricas e incógnitas" (GANDÍA, 1929, p. 124). Ou seja, a busca pelo índio dourado não estava ligada apenas às práticas indígenas de outrora, mas também às experiências e conquistas anteriores.

À história de El Dorado foram associadas notícias de diversas fontes e todas se juntavam a um mesmo nome em comum. Gandía afirma que El Dorado foi aplicado às diversas fontes de ilusão que em nada se relacionavam com a primitiva cerimônia do cacique Guatavita. Chamaram de El Dorado diversas regiões auríferas e argentíferas de várias partes da América, desde os ricos túmulos de Zenú, aos Templos do Sol dos Chibchas e dos Incas, incluindo nessa perspectiva, países inexplorados sobre os quais corriam falsos rumores de riquezas e tudo que fosse misterioso.

Gandía pontua que as primeiras expedições empreendidas pelos Welsers, antes do ano de 1535, em que, Luis Daza encontrou o índio em Bogotá, e que foi relacionada à história do cacique dourado, não foi em busca de El Dorado, mas sim de conquistas que prometiam grandes descobrimentos. À designação "El Dorado" estão atreladas diversas riquezas que ao longo de inúmeras expedições acabou se metamorfoseando e dando origem ao mito de uma cidade que seria completamente composta de ouro, como também a lenda do cacique banhado de ouro que seguia numa balsa e submergia na lagoa. À Província da Meta se funde a de El Dorado, porque ambas se referem a territórios cobiçados por suas riquezas auríferas incalculáveis.

Outro aspecto que pode ter levado os conquistadores a acreditarem que existia uma região de inúmeras riquezas pode estar ligado às ações indígenas. Durante o processo de conquista do Quito, os habitantes daquele território tinham conhecimento ${ }^{20}$ dos

\footnotetext{
20 PÁEZ, José Roberto. Cronistas Coloniales: (Segunda Parte)/ [Estudio, biografías y selecciones de J. Roberto Páes]. Disponível em: <http://www.cervantesvirtual.com/obra/cronistas-coloniales-segunda-parte--0/>. Acesso em: 10/07/2014.
} 
movimentos e da chegada dos espanhóis, que eram vigiados a todo o momento. Yrruminavi tomou a ação de abandonar o território por saber da ganância e obsessão espanhola pela busca de ouro e outros metais preciosos. Assim as práticas violentas dos conquistadores contra os indígenas eram motivos razoáveis para que os índios fizessem com que os espanhóis se perdessem nas florestas e consequentemente fossem eliminados pela fome e difíceis condições intempéries. Os habitantes daqueles diferentes territórios podem não ter alimentado o mito, todavia a busca aurífera dos conquistadores pode ter suscitado nos habitantes do Quito uma tentativa de aniquilação dos espanhóis.

Um traço elementar que encontramos nas obras de Gandía e Ramos Perez é a afirmação contundente de que as expedições primitivas em nada se relacionavam com o mito doradista e afirmação categórica da inexistência de El Dorado. Os conquistadores analisados investiram em suas buscas exatamente pela crença de que o ouro, prata e especiarias seriam encontrados. Desde o momento em que surgiram as primeiras informações da Meta, ficou evidente que Diego de Ordás havia calculado e planejado empiricamente a busca por uma região de alta produção aurífera.

O fato de atrelarem a busca da Meta às expedições empreendidas posteriormente por Sebastian de Benalcazar e Gonzalo Pizarro demonstram que o caráter fabuloso foi produzido inicialmente pelos próprios conquistadores e que alimentou o imaginário dos cronistas posteriores. As empresas decorrentes que se dedicaram à busca de El Dorado se ancoravam nos relatos anteriores e mesmo que a província e/ou cacique dourado nunca fossem encontrados, os conquistadores não cessavam, porque os tesouros de Tenochtitlán e do Peru eram conquistas incisivas para perpetuar a crença.

\section{Considerações finais}

Concluímos através do estudo crítico das fontes e da historiografia acerca da busca de El Dorado que, a procura pelas Províncias da canela, do Dourado e lagoa do dourado revelam traços da primeira Modernidade tão relevantes quanto o próprio mito. A transição do Medievo para a Modernidade mostrou-se gradual e aqueles castelhanos quinhentistas ainda carregavam consigo uma grande bagagem da sociedade medieval. O impacto dessas influências se mostrou efetivo nas ações dos expedicionários, pois atrelados aos seus intentos havia uma mescla entre experiência e fábula.

Os conquistadores se lançavam em seus empreendimentos com objetivos nem sempre confirmados, porém a experiência acumulada fazia com que eles prosseguissem confiantes. Os territórios de Tenochtitlán e do Peru tinham se mostrado proeminentes em riquezas e maravilhas e, por mais espantosas que fossem as práticas, ritos e hábitos indígenas, eram esses aspectos que reforçavam a crença de que coisas jamais vistas pudessem ser encontradas. As leituras e os conhecimentos da Antiguidade Clássica serviram de subsídio para interpretar e traduzir alguns costumes alheios à cultura europeia do século 
XVI. Os expedicionários buscavam acrescer méritos aos seus feitos e com isso se apropriavam das ocorrências anteriores para justificar seus êxitos ou fracassos. O contágio das ideias precedentes foi vultoso para que o mito difundisse e agregasse aspectos que não tinham qualquer ligação com ele.

A Provincia del Dorado ou Laguna del dorado foram denominações utilizadas para referenciar regiões cujas riquezas seriam incomensuráveis. Concordamos com Ramos Perez e Gandía quando ambos afirmam que as expedições primitivas não objetivaram uma cidade dourada ou o cacique da lagoa Guatavita, ao contrário eles estavam aplicando suas experiências aos seus intentos. Os castelhanos não se empenhavam em uma busca sem sentido, cada uma das expedições tinha um objetivo definido, mesmo que esse objetivo nem sempre pudesse ser encontrado. Quando Ordás empreendeu a busca pela Província da Meta, calculou e analisou criteriosamente cada passo para que enfim pudesse seguir em viagem. O mesmo ocorre na busca de Benalcazar que tinha por foco encontrar o Quito e, aquele território, prometia riquezas inigualáveis.

A historiografia corrobora a análise sobre os cronistas que versaram sobre El Dorado e, as narrações que foram objeto desse trabalho não fazem referência à busca de um país dourado. Quando foi evidenciada a busca de um índio ou lagoa dourada, ambos serviam como referencial das riquezas vinculadas a um determinado território. Ou seja, o objetivo dos conquistadores continuava sendo as incomensuráveis riquezas auríferas.

O que possibilita a concretização do mito de El Dorado é o contágio das ideias precedentes e a apropriação distorcida delas. Tal como Ramos Perez assevera, à medida que as promessas não se cumpriam e as riquezas não eram encontradas, o maravilhoso encontrava brechas para que novos elementos fossem fomentados. A junção de elementos racionais e fabulosos incidiu sobre os relatos posteriores e criou uma região que jamais existiu. El Dorado transformou-se numa região ignota, que a cada nova empresa se movia para outra região completamente diferente. El Dorado nunca existiu, tratava-se de um vocábulo para regiões ignotas e paradiśacas, mas os intentos que o circundam fizeram com que ele crescesse e ganhasse importância destacada na primeira Modernidade.

Artigo recebido em 08/07/2016

Aprovado para publicação em 08/09/2016 
94 Crônicas de El Dorado: Uma análise dos relatos dos cronistas espanhóis sobre uma terra de riquezas fabulosas na América do Sul (1536-1542)

\section{Referências}

\section{Fontes Documentais}

BECCO, H. J. Crônicas De El Dorado: Selección, prólogo y notas. Caracas: Biblioteca Ayacucho, 2003. Disponível em:

<http://www.bibliotecayacucho.gob.ve/fba/index.php?id=97\&backPID=96\&swords=cronicas \%20de\%20el\%20dorado\&tt_products=246>. Disponível em:

<http://bib.cervantesvirtual.com/servlet/SirveObras/23586289872392741254679/index.htm >. Acesso em: 12 jan. 2014.

HERRERA Y TORDESILLAS, Antonio. Historia General de los hechos de los Castellanos en las Islas y tierra firme del Mar Océano. Década IV. Disponível em: <http://cdigital.dgb.uanl.mx/la/1080012370_C/1080012371_D2/1080012371_D2.html.>. Acesso em: 20 dez. 2014.

Historia General de los hechos de los Castellanos en las Islas y tierra firme del Mar Océano. Década V. Disponível em: <http://www.cervantesvirtual.com/obra/historia-generalde-los-hechos-de-los-castellanos-en-las-islas-y-tierra-firme-del-mar-oceano/>. Acesso em: 20 jun. 2014.

MEDINA, José Toribio. Descubrimiento del Río de las Amazonas. Oficina de E. Rasco, Bustos Tavera, 1, 1894. Disponível em:

<https://archive.org/stream/raha_103310\#page/n7/mode/2up z. Acesso em: 13 jan. 2014.

OVIEDO Y VALDÉS, Gonzalo Fernández. Historia Natural y General de las Indias: Tomo Primero de la Segunda Parte, segundo de la obra (1478-1557). Disponível em: <https://archive.org/details/historiageneral01fernguat>. Acesso em: 13 jan. 2014.

Historia Natural y General de las Indias: Tercera Parte. (1478-1557) - TOMO IV. Disponível em: <https://archive.org/details/mobot31753000521697>. Acesso em: 13 jan. 2014.

\section{Bibliografia}

AínSA, Fernando. De la Edad de Oro a El Dorado: Génesis del discurso utópico americano. Tierra Firme, 1998.

CHARTIER, Roger. O mundo como representação. Estudos Avançados, vol.5, n.11, 1991.

FRANCO JR., Hilário. As utopias medievais. São Paulo: Brasiliense, 1992.

GANDIA, Enrique. Historia crítica de los mitos de la conquista americana. Buenos Aires: Juan 
Roldan, 1929.

GIL, Juan. Mitos e utopías del descubrimiento. Vol.III: "El Dorado". Madrid, Alianza Editorial, 1989.

GIUCCI, Guillermo. Frei Gaspar de Carvajal. São Paulo: Scritta Editorial, 1992.

GREENBLATT, Stephen. Possessões maravilhosas (trad.). São Paulo: Edusp, 1996.

LANCIANNI, Giulia. O maravilhoso como critério de diferenciação entre sistemas culturais. Revista Brasileira de História. São Paulo, n.21, 1991.

LANGER, Johnni. O mito do Eldorado: Origem e Significado do Imaginário Sul-Americano (Século XVI). Revista de História. 136. FFLCH-USP, 1997.

LE GOFF, Jacques. O Maravilhoso e o Quotidiano no Ocidente Medieval. Rio de Janeiro, Edição 70, 1983.

LE GOFF, Jacques; SCHMITT, Jean Claude. Dicionário Temático do Ocidente Medieval. São Paulo: Edusc, 2002.

MATOS, Maria Izilda S. De. Viagens pelo Rio Amazonas. Estudos Ibero-Americanos, PUCRS, v. 38, supl., p. S189-S198, nov. 2012.

RAMOS PEREZ, Demetrio. El mito Del Dorado: su genesis y proceso. Caracas: Biblioteca de la Academia Nacional de la Historia, 1973.

RESTALL, Matthew. Sete Mitos da Conquista da Conquista Espanhola. Rio de Janeiro: Civilização Brasileira, 1964. 